\title{
1. Reinforcing the 'social' in social marketing
}

\author{
Lukas Parker and Linda Brennan
}

\section{SO WHAT IS SOCIAL MARKETING?}

Commercial marketing uses tools and techniques from a variety of disciplines to encourage people to behave in ways that achieve the aims of commercial organisations (e.g. buying products). The use of these techniques to foster socially desirable outcomes was a natural extension. This use of marketing for social purposes was eventually termed 'social marketing' and is now conceptualised as:

\begin{abstract}
Social Marketing seeks to develop and integrate marketing concepts with other approaches to influence behaviours that benefit individuals and communities for the greater social good. Social Marketing practice is guided by ethical principles. It seeks to integrate research, best practice, theory, audience and partnership insight, to inform the delivery of competition sensitive and segmented social change programmes that are effective, efficient, equitable and sustainable. (International Social Marketing Association, 2018)
\end{abstract}

The earliest social marketing campaigns commonly used commercial marketing practices and theories. However, the commercialisation and use of social marketing throughout the 1980s and 1990s led to much angst about the role of social marketing in addressing issues of social good (Truss, Marshall \& Blair-Stevens, 2010).

Social marketing is a term that was first used in the 1960 s by health professionals (Khan \& Choldin, 1965) for family planning programmes with the goal of decreasing population growth. Social marketing was (re)appropriated into the marketing discipline by Kotler and Zaltman's (1971) article 'Social marketing: An approach to planned social change'. This article initiated the shift from family planning towards a more holistic model of marketing. This new approach cemented the conventional commercial marketing mix approach (or the 'four Ps' approach) as central to social marketing campaigns. Social marketing under this model included a greater array of Ps than merely promotion 


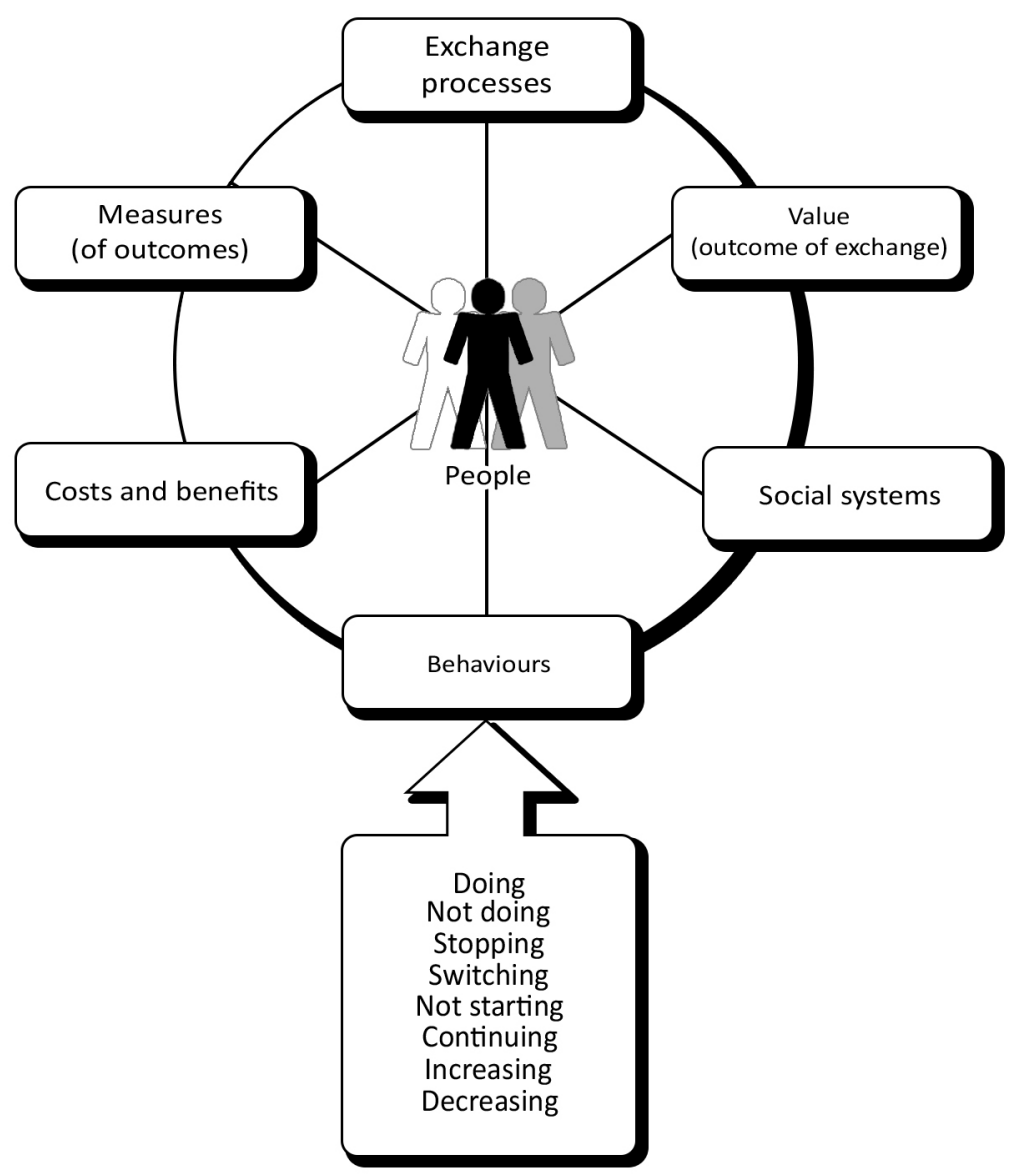

Source: Adapted from Brennan, Binney, Parker, Aleti \& Nguyen, 2014.

\section{Figure 1.1 The social dominant logic}

- although product, price and distribution were also concerns of the pre-1970s social marketers (Choldin, 1967).

The use of social marketing to shape social contexts is not new (Domegan \& Brodie, 2008), however, social marketers are increasingly seeking societal-level change, not simply individual behaviour change. Macro-social marketing has moved into considerations of systemic social change, aiming to renegotiate the norms and institutions of society to foster new sets of behaviours and social norms (Brennan et al., 2014; Kennedy, 2016). Social marketing can be under- 
taken by governments, non-profit and for-profit entities. The creation of new norms provides institutional support to developing behavioural infrastructure to underpin these new norms (Domegan et al., 2016).

Social marketing is about seeking social good. However, as Polonsky (2017) points out, not everyone agrees on what social good is, or how it can be achieved. Polonsky uses an example of programmes that enhanced quality of life but simultaneously degraded local cultures. Brennan and Binney (2008) also question the impact of increasing material well-being on the environmental sustainability of Earth.

Andreasen (2012) summarised the relationship between commercial and non-commercial marketing and argued for a social dominant logic (Figure 1.1). Andreasen argued that by placing people (back) at the centre of the exchange process, there is no longer a need to differentiate beyond the 'product', because the outcome (value) is more important than any of the inputs. This idea has not evolved further, and the service-dominant logic has prevailed (e.g. French \& Russell-Bennett, 2015; Lefebvre \& French, 2012; Luca, Hibbert \& McDonald, 2015; Russell-Bennett, Gordon, Wood \& Previte, 2013).

In Andreasen's social dominant view, exchange takes place within the social system. That is, people engage and interact with each other to create value. In social marketing, as in commercial marketing, organisations seek some form of behaviour change (at micro, meso or macro levels). While commercial marketers may be seeking to increase consumption, and sometimes social marketing may be working hard to decrease the same behaviour, behaviour change remains the core of marketing activities. However, unless those behaviours deliver value to the consumer or marketer, they will not be changed. The costs and benefits of the exchange processes are therefore important to consider. The interchange must be considered valuable enough to participate in by either party to the exchange.

\section{WHAT SOCIAL MARKETING IS NOT}

Any discussion about what social marketing is necessarily involves a discussion about what it is not. Especially given that social marketing has broadened its definitions to include almost everything available in the business toolkit, from intentions and principles to actions and outcomes.

Social marketing is not corporate social responsibility (CSR). While there is no currently agreed definition on what is and what is not CSR (Sanclemente-Téllez, 2017), CSR is broadly defined as a set of activities that a corporation undertakes to meet their responsibilities to the societies in which they operate. According to the Australian Human Rights Commission (2008): ' $\mathrm{CSR}$ is generally understood to mean that corporations have a degree of responsibility not only for the economic consequences of their activities, but 
also for the social and environmental implications. This is sometimes referred to as a "triple bottom line" approach that considers the economic, social and environmental aspects of corporate activity.' Thus, CSR is not about marketing, although it clearly has market impacts and is often managed in conjunction with marketing within the corporation. In this conceptualisation, the goal of CSR is to meet social obligations, not enhance market status or create market outcomes.

Social marketing is also not 'corporate social marketing'. Corporate social marketing is profit-driven, whilst social marketing is driven by a desire for social good. This is not to say that corporations cannot be socially driven many social enterprises trade off profits for social good. However, a profit motive is likely to create tensions between the goals of the corporation and social marketers - for example, consider the tensions between a water supply company aiming to increase profit, and social marketers aiming to decrease the use of water on household gardens (Polonsky, 2017). Notwithstanding these possible tensions, Polonsky (2017) also asserts that there is no reason why for-profit organisations cannot also be leaders in social marketing initiatives, especially as they have significant access to resources and should have a vested interest in decreasing harms to their constituents and consumers.

The other type of 'social' marketing that causes confusion is social media marketing. Social media marketing is the use of supporting technologies that facilitate the connections between individuals and their social networks in marketing. Social media includes platforms (e.g. Facebook, TikTok or Instagram), systems (websites, infrastructure, services) devices (computers, phones and tablets) and affordances (e.g. blogging, connecting, sharing). Social media is largely funded by paid advertising (Murschetz, 2020), although it does not necessarily involve active participant engagement with advertisements (Fernandes \& Castro, 2020). Consequently, social media may be a tool used in social marketing, but it is only one of the many tools available (see Chapter 4 for the social marketing toolkit).

This book provides an overview of social media in social marketing to assist social marketing practitioners and researchers to design effective programmes. It deliberately takes a 'social' approach to social marketing, moving beyond individual approaches. However, it also focuses on downstream social marketing activities, because social media facilitates social networking mostly between individuals.

\section{BOOK STRUCTURE}

Chapter 2 outlines social marketing planning frameworks and outlines approaches to behaviour change within a systems-based framework. The chapter provides an overview of a behavioural ecological model and suggests 
ways the model can be used to develop social marketing programmes. The chapter highlights a humanistic approach to social marketing strategy and planning and outlines the use of social media to create bi-directional influences in the human behaviour system.

Chapter 3 provides an overview of the mechanics of social media and discusses how social media can be used in social marketing programmes. Core concepts such as virality and influence are presented as well as the opportunities and challenges for social marketing in high-paced digital environments.

Chapter 4 presents a conceptual framework for designing social marketing advertising campaigns. The chapter provides three real-world examples of successful social advertising campaigns from an agency with long-standing success in social marketing.

Chapter 5 explains the foundational theories of emotions that are most often employed in social marketing. These theories are outlined in relation enhancing the effectiveness of social marketing via social media platforms. The chapter gives a broad overview of emotions in advertising as well as definitions and classifications useful in designing social marketing programmes for change.

Chapter 6 summarises the key social marketing advertising appeals of fear, guilt and shame. The chapter describes the kinds of negative appeals used in social marketing and emphasises the compelling nature of threat appeals. The chapter also highlights some unintended consequences of the use of threat appeals in social marketing that may be useful for future campaign designers.

Chapter 7 explores the use of positive emotions in social marketing communications. While positive emotions are seldom used in social marketing, they are growing in precedence, and can be useful in creating sustainable, self-determined behaviour change. Humour is one form of positive emotion that has widespread application in social marketing. The chapter therefore describes the mechanics of using humour as an appeal in social marketing.

Chapter 8 investigates storytelling for social marketing on social media applications. Stories are the key to social media sharability, and therefore a means by which social marketers can establish social links with and between online communities. The chapter provides a set of guidelines for developing online social marketing stories.

Chapter 9 concludes the book with a discussion of ethical frameworks behind social marketing practice. The chapter highlights that some means of communication are potentially problematic from a moral and ethical standpoint, and provides guidelines for 'good' communication practice designed to foster social good. Rather than providing rigid moral structures, the chapter is designed to foster discussion and provide considerations over the ethics of social marketing and social media. 


\section{REFERENCES}

Andreasen, A. R. (2012), 'Rethinking the relationship between social/nonprofit marketing and commercial marketing', Journal of Public Policy and Marketing, 31(1), 36-41.

Australian Human Rights Commission (2008), Corporate Social Responsibility and Human Rights, accessed 31 May 2018 at www.humanrights.gov.au/our-work/ corporate-social-responsibility-human-rights

Brennan, L., \& Binney, W. (2008), 'Concepts in conflict: Social marketing and sustainability', Journal of Nonprofit and Public Sector Marketing, 20(2), 261-81.

Brennan, L., Binney, W., Parker, L., Aleti, T., \& Nguyen, D. (2014), Social marketing and behaviour change: Models, theory and applications, Cheltenham, UK and Northampton, MA, USA: Edward Elgar Publishing.

Choldin, H. M. (1967), 'Development at the grass roots: A report of a panel discussion', Community Development Journal, 2(6), 39-44.

Domegan, C., \& Brodie, R. (2008), 'Social marketing: Implications for contemporary marketing practices classification scheme', Journal of Business and Industrial Marketing, 23(2), 135-41.

Domegan, C., McHugh, P., Devaney, M., Duane, S., Hogan, M., Broome, B. J., Layton, R. A., Joyce, J., Mazzonetto, M., \& Piwowarczyk, J. (2016), 'Systems-thinking social marketing: Conceptual extensions and empirical investigations', Journal of Marketing Management, 32(11-12), 1123-44.

Fernandes, T., \& Castro, A. (2020), 'Understanding drivers and outcomes of lurking vs. posting engagement behaviours in social media-based brand communities', Journal of Marketing Management, 13(1), 1-22.

French, J., \& Russell-Bennett, R. (2015), 'A hierarchical model of social marketing', Journal of Social Marketing, 5(2), 139-59.

International Social Marketing Association (2018), Consensus definition of social marketing, accessed 27 March 2019 at www.i-socialmarketing.org/social-marketing -definition\#.Ww9hMFOFNTY

Kennedy, A.-M. (2016), 'Macro-social marketing', Journal of Macromarketing, 36(3), 354-65.

Khan, A. M., \& Choldin, H. M. (1965), 'New “family planners” in rural East Pakistan', Demography, 2(1), 1-7.

Kotler, P., \& Zaltman, G. (1971), 'Social marketing: An approach to planned social change', Journal of Marketing, 35(3), 3-12.

Lefebvre, R. C., \& French, J. (2012), 'Transformative social marketing: Co-creating the social marketing discipline and brand', Journal of Social Marketing, 2(2), 118-29.

Luca, N. R., Hibbert, S., \& McDonald, R. (2015), 'Towards a service-dominant approach to social marketing', Marketing Theory, 16(2), 194-218.

Murschetz, P. C. (2020), 'State aid for independent news journalism in the public interest? A critical debate of government funding models and principles, the market failure paradigm, and policy efficacy', Digital Journalism, 1-20, DOI 10.1080/21670811.2020.1732227.

Polonsky, M. J. (2017), 'The role of corporate social marketing', Journal of Social Marketing, 7(3), 268-79.

Russell-Bennett, R., Gordon, R., Wood, M., \& Previte, J. (2013), 'Fresh ideas: Services thinking for social marketing', Journal of Social Marketing, 3(3), 223-38. 
Sanclemente-Téllez, J. C. (2017), 'Marketing and corporate social responsibility (CSR), Moving between broadening the concept of marketing and social factors as a marketing strategy', Spanish Journal of Marketing - ESIC, 21(1), 4-25.

Truss, A., Marshall, R., \& Blair-Stevens, C. (2010), A history of social marketing, reprinted in J. French, C. Blair-Stevens, D. McVey \& R. Merritt (eds), Social marketing and public health: Theory and practice, Oxford: Oxford University Press. 